\title{
COMBINED MITRAL AND TRICUSPID STENOSIS IN 47-YEAR OLD RHEUMATIC VALVULAR HEART DISEASE PATIENT: A CASE REPORT
}

\author{
${ }^{1}$ Ejeagba $\mathrm{OO},{ }_{,}^{1}$ Ayoola $\mathrm{YA},{ }^{1}$ Ejeh $\mathrm{AB},{ }_{,}^{1}$ Adamu A, ${ }^{1}$ Okolie $\mathrm{HI},{ }^{2}$ Danbauchi SS
}

${ }^{1}$ Department of medicine, Federal Teaching Hospital, Gombe, Gombe State. Nigeria ${ }^{2}$ Department of Internal Medicine, Jos University Teaching Hospital, Jos, Plateau State. Nigeria.

Correspondences and reprint request to: Dr Ayoola Yekeen Ayodele, Department of Medicine, Federal Teaching Hospital, PMB 0037, Gombe, Gombe State, Nigeria.

E-mail: profyekeen@yahoo.com_Phone:+2348066612875

\begin{abstract}
Background: Rheumatic valvular heart disease is a common complication of rheumatic fever; however combined mitral and tricuspid stenosis is an extremely rare form of multi-valve disease presentation. Case Presentation: We report a case of combined mitral and tricuspid stenosis from rheumatic heart disease (RHD) in a 47-year-old woman who was being managed for hypertensive heart disease (HHDx) on anti-hypertensives for 2 yrs prior to presentation. However, on further review with transthoracic echocardiography (TTE), she was found to have thickened mitral valve and hockey stick appearance with dilated left atrium (dimension of $60 \mathrm{~mm}$ ) and reduced left ventricular ejection fraction (LVEF) of $45 \%$. A repeat TTE done 8 years after the first one showed a severely dilated left atrium (LAD 71 mm) with estimated area of $55.4 \mathrm{~cm}^{2}$; moderate mitral stenosis and severe tricuspid stenosis with moderate TR. The LVEF was $29 \%$ with a severe right ventricular (RV) systolic dysfunction (TAPSE of $9 \mathrm{~mm}$ ). Patient is being managed conservatively due to economic constraints and the likelihood of very poor surgical outcome due to severe biventricular dysfunction. Conclusion: The case is reported for its rarity as well as the importance of interval evaluation of unaffected valves in a setting of single valve disease for early detection and possible prompt treatment and intervention.
\end{abstract}

Keywords: Mitral Stenosis, Multi-valve disease, Rheumatic heart Disease, Tricuspid Stenosis

\section{INTRODUCTION}

Rheumatic heart disease is a global cause of morbidity and mortality especially in developing countries. ${ }^{1}$ It affects people who had rheumatic fever that was not properly treated and/or did not receive penicillin prophylaxis. The mitral valve is most commonly affected in single-valve disease whereas in multi-valve disease the mitral and aortic valves are most commonly affected. ${ }^{2}$ Combined

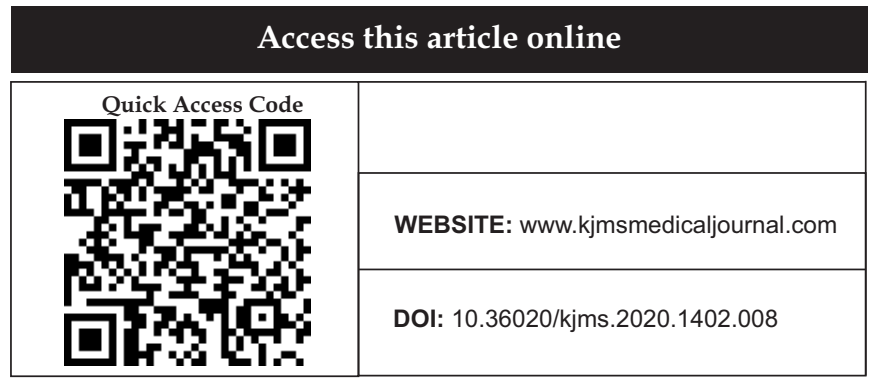

stenosis of the mitral and tricuspid valves is a very rare complication of rheumatic heart disease. ${ }^{3,4}$

\section{CASE PRESENTATION}

A $47 y$ r woman who presented to the cardiology clinic of our facility, Federal Teaching Hospital via the GOPD 8yrs ago on self- referral from a tertiary facility where she has been on follow up for hypertensive heart disease on anti-hypertensives for $2 y$ rs. She presented with symptoms of worsening dyspnoea, cough with haemoptysis and palpitations. She was diagnosed hypertensive 2 yrs prior and not diabetic. Family history is significant for hypertension in both paternal grand parents. She is Para $6^{+1} 2$ alive, had two 
caesarean section on account of antepartum haemorrhage and four children died from febrile illnesses. Her childhood history was not remarkable.

On physical examination positive findings were irregularly irregular pulse with a rate of $96 \mathrm{~b} / \mathrm{min}$, blood pressure (BP) of $120 / 80 \mathrm{mmHg}$, normal jugular venous pressure, displaced apex at $7^{\text {th }}$ left intercostal space anterior axillary line heaving with grade 4/6 apical pan-systolic murmur and a diastolic murmur at the left sternal border. The patient also has a loud P2 and tenderness in right upper abdominal quadrant. A diagnosis of rheumatic mixed mitral valve disease predominantly regurgitation and HHDx was made.
Transthoracic echocardiography (TTE) done 8 yrs ago revealed rheumatic mixed mitral valve disease with thickened, hockey sticklike mitral valve with dilated left atrium $(60 \mathrm{~mm})$ and reduced EF $(45 \%)$. A repeat TTE 8 years later showed the following features : severely dilated LAD $(76 \mathrm{~mm})$ with estimated area of $55.4 \mathrm{~cm}^{2}$ (figure 1); moderate mitral stenosis with restricted posterior leaflet (Mitral valve area (MVA) by planimetry of $2.6 \mathrm{~cm}^{2}$ and mean gradient of $9.3 \mathrm{mmHg}$; thickened left ventricular posterior wall diameter in diastole of $1.4 \mathrm{~cm}$; LVEDD of $5.5 \mathrm{~cm}$; global hypokinesia with LVEF of $29 \%$ and posteriorly directed jet of moderate regurgitation; severely dilated right atrium $10.2 \mathrm{~cm}$; severe tricuspid stenosis and moderate TR with a Vmax of $2.88 \mathrm{~m} / \mathrm{s}$ and PPG of 33.23mmHg (Figure 2);

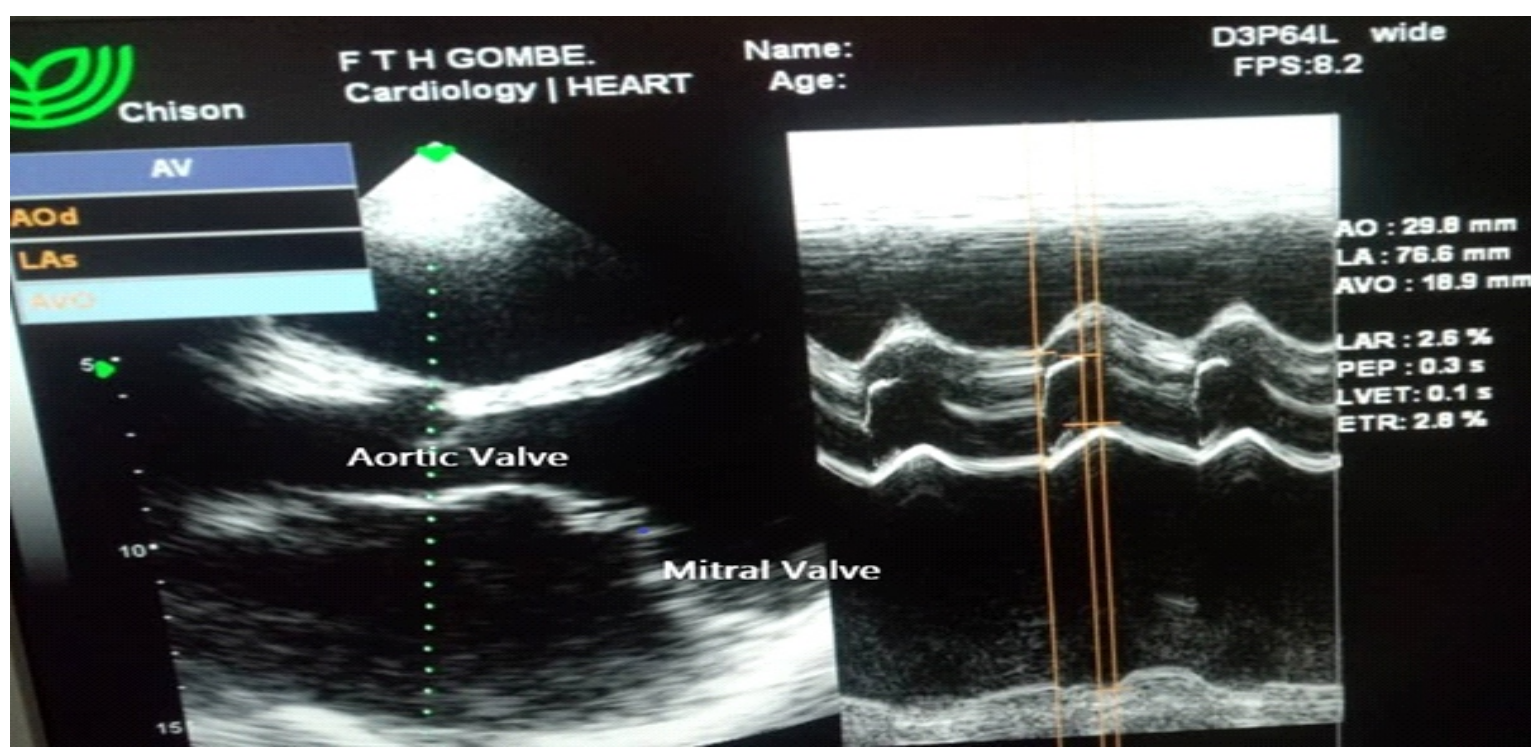

Figure 1: Severely dilated left atrium and thickened mitral valve

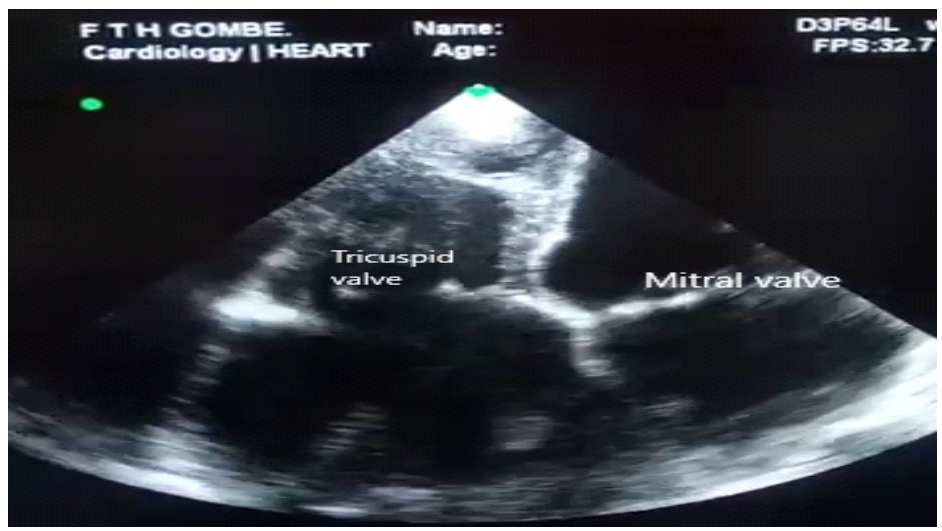

Figure 2: Thickened tricuspid valve and dilated right atrium. 
PASP of $53.23 \mathrm{mmHg}$ using estimated RAP of $20 \mathrm{mmHg}$; dilated $\mathrm{RV}$ with diameter of $5.4 \mathrm{~cm}$ and severe RV systolic dysfunction with TAPSE of $9 \mathrm{~mm}$. Pulmonary valve is thin and pliable with mild regurgitation but no evidence of stenosis. Electrocardiography (ECG) done serially showed atrial fibrillation (AF) with slow ventricular response and multifocal VPCs. Serial E/U/Cr, fasting lipid profiles and urinalysis were not remarkable.

She could not be referred for surgical treatment due to economic constraints and was managed conservatively on anti-heart failure regimen. Over the $8 \mathrm{yr}$ period she had one hospital admission about 8years prior to our review and was fairly stable until 3yrs ago when she started having symptoms of abdominal swelling and worsening dyspnoea with productive cough. She was referred for surgical review and possible valve replacement/repair where after evaluation the cardiothoracic surgeon requested for a second opinion in a facility with ventricular assist devices in view of likely very poor surgical outcome due to severe biventricular dysfunction.

\section{DISCUSSION}

Rheumatic valvular heart disease is a common complication of acute rheumatic fever (ARF) and is associated with high morbidity and mortality. ${ }^{5}$ Although the incidence of ARF has drastically reduced in high income countries, chronic rheumatic heart disease still represents $22 \%$ of valvular heart disease in Europe. ${ }^{6}$ RHD still remains a major disease burden in developing nations including sub-Saharan Africa (SSA), commoner in females although Akpa et.al reported higher prevalence in males in Port Harcourt southern Nigeria. ${ }^{8}$ In Nigeria the prevalence of RHD has dropped significantly over the years in southern part of the country but remain relatively higher in the northern part., ${ }^{9,10}$

Studies from different parts of the country have reported mitral valve as the most commonly affected in single valve disease whereas mitral and aortic valves are mostly involved in combined valve disease. . $^{5,8,11}$

Isolated tricuspid valve involvement in RHD is extremely rare and in some Nigerian series none was documented. ${ }^{12}$ Sultan et al in an evidencebased systematic overview of 2,497 RHD patients, found $7.7 \%$ (193) of them to have tricuspid valve involvement with $93.3 \%$ of them associated mitral RHD. This suggest that involvement of the tricuspid valve, though rare, may not be uncommon. ${ }^{12}$

In a study in the USA, combined mitral stenosis and aortic stenosis $(15 \%)$ is the commonest followed by combined mitral stenosis and aortic regurgitation (6\%). Others are combined pure mitral regurgitation and pure aortic regurgitation (4\%), combined aortic stenosis and pure mitral regurgitation $(2 \%)$, combined tricuspid, mitral and aortic valve stenosis (2\%) and combined tricuspid valve stenosis and mitral valve stenosis $(0.40 \%){ }^{13}$

Combined mitral and tricuspid stenosis is

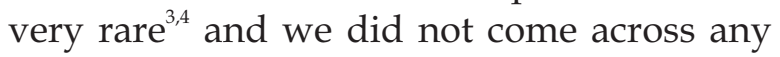
reported case emanating from Nigeria, thus to the best our knowledge this might be the first reported case of combined rheumatic mitral and tricuspid stenosis in Nigeria.

The condition could be treated with good outcome with balloon valvuloplasty and/or surgical replacement/repair. ${ }^{4}$ However, our index patient could not get surgical intervention due to financial constraint as she could not afford treatment which is mainly out-of-pocket funding.

\section{CONCLUSION}

Rheumatic heart disease is still a major cause of morbidity and mortality especially in developing countries and efforts at controlling acute rheumatic fever and preventing complications would go a long way in reversing the unfavourable indices. This can be achieved if African nations would adopt the Drakensberg Declaration ${ }^{14}$ on the control of rheumatic fever and rheumatic heart disease in Africa.

\section{ETHICAL CONSIDERATION}

Verbal consent was taken from the patient after adequate explanation was made. 


\section{ACKNOWLEDGMENTS}

None

\section{CONFLICTS OF INTEREST}

The authors have no conflicts of interest to declare.

\section{AUTHORS' CONTRIBUTION}

All the authors have made substantial contributions to the patient's management and conception of the work. Drafting the manuscript was made my EOO, AYA and DSS with inputs from other authors. It was revised critically for important intellectual content and all authors read and approved the final manuscript.

\section{REFERENCES}

1. Zühlke L, Engel ME, Karthikeyan G, Rangarajan S, Mackie P, Cupido B, et al. Characteristics, complications, and gaps in evidence-based interventions in rheumatic heart disease: the Global Rheumatic Heart Disease Registry (the REMEDY study). Euro Heart J. 2014;36(18):1115-22.

2. Watkins DA, Johnson CO, Colquhoun SM, Karthikeyan G, Beaton A, Bukhman G, et al. Global, Regional, and National Burden of Rheumatic Heart Disease, 1990-2015. N Engl J Med. 2017;377(8):713-22.

3. Biplab P, Pranab K, Biswas BM. A rare combination of rheumatic mitral and tricuspid stenosis treated by percutaneous balloon valvuloplasty. J Indian Coll Cardiol 2015; 5:32-4.

4. Roberts WC, Sullivan MF. Combined mitral valve stenosis and tricuspid valve stenosis: morphologic observations after mitral and tricuspid valve replacements or mitral replacement and tricuspid valve commissurotomy. Am J Cardiol 1986;58(9):850-2.

5. Danbauchi SS, Alhassan MA, David SO, Wammanda R, Oyati IA. Spectrum of rheumatic heart disease in Zaria. Ann Afr Med 2004; 3(1):1721.

6. Iung B, Vahanian A. Epidemiology of Acquired Valvular Heart Disease. Can J Cardiol 2014Sep;30(9):962-70.

7. Coffey S, Rayner J, Newton J, Prendergast BD. Right-sided valve disease .Int J Clin Pract, 2014; 68(10):1221-1226

8. Akpa M, Dodiyi-Manuel S, Agada Z, Odia

O. Rheumatic heart disease in Port Harcourt, Nigeria: clinical, demographic and echographic features. Port Harcourt Med J 2012; 6:3.

9. Akinwusi P, Peter JO, Oyedeji AT, Odeyemi AO. The new face of rheumatic heart disease in South West Nigeria. Int J Gen Med 2013; 6:375-81.

10. Ogah OS, Stewart S, Falase AO, Akinyemi JO, Adegbite GD, Alabi AA, Ajani AA, Adesina JO, Durodola A, Sliwa K. Contemporary Profile of Acute Heart Failure in Southern Nigeria: Data From the Abeokuta Heart Failure Clinical Registry. JACC Hear Fail 2014 Jun 1;2(3):250-9.

11. Sani MU, Karaye KM, Borodo MM. Prevalence and pattern of rheumatic heart disease in the Nigerian savannah: an echocardiographic study. Cardiovasc J Afr 2007; 18(5):295-9.

12. Sultan FAT, Moustafa SE, Tajik J, Warsame T, Emani U, Alharthi M, et al. Rheumatic tricuspid valve disease: an evidence-based systematic overview. J Heart Valve Dis 2010 May; 19(3):374-82.

13. Roberts WC. Morphologic features of the normal and abnormal mitral valve. Am J Cardiol1983 Mar 15; 51(6):1005-28.

14. Mayosi B, Robertson K, Volmink J. et al. The Drakensberg declaration on the control of rheumatic fever and rheumatic heart disease in Africa. S Afr Med J. 2006;96: 246-246.

Cite this article as: Ejeagba OO, Ayoola YA, Ejeh AB, Adamu A, Okolie HI, Danbauchi SS. Combined Mitral and Tricuspid Stenosis in 47-Year Old Rheumatic Valvular Heart Disease Patient: A Case Report. KJMS 2020; 14(2): 153 - 156. 